\title{
Honey and Propolis have Antifungal Property against Select Dermatophytes and Candida albicans
}

\author{
Maria Christina R. Batac, ${ }^{1,2}$ Mary Ann C. Sison, ${ }^{2}$ Cleofas R. Cervancia ${ }^{3,4}$ and Marie Eleanore O. Nicolas ${ }^{5}$ \\ ${ }^{1}$ Section of Dermatology, Department of Medicine, College of Medicine and Philippine General Hospital, University of the Philippines Manila \\ ${ }^{2}$ Department of Medical Microbiology, College of Public Health, University of the Philippines Manila \\ ${ }^{3}$ APIMONDIA Regional Commission for Asia \\ ${ }^{4}$ Institute of Biological Sciences, College of Arts and Sciences, University of the Philippines Los Baños \\ ${ }^{5}$ Asian Hospital and Medical Center
}

\begin{abstract}
Objective. To determine the antifungal properties of honey from two different floral sources (sunflower and coconut) and Philippine propolis against selected dermatophytes and Candida albicans.
\end{abstract}

Methods. The minimum inhibitory concentration (MIC) of honey and propolis against Trichophyton rubrum, T. mentagrophytes, Microsporum gypseum, Epidermophyton floccosum and Candida albicans was determined using the broth macrodilution method (NCCLS M38-P). Disk diffusion method was used to determine the zones of inhibition. Clotrimazole served as comparator drug.

Results. Sunflower and coconut honey inhibited all test fungi, with coconut honey yielding lower MICs. However, propolis performed better than both sunflower and coconut honey. T. mentagrophytes was most sensitive to the test agents. Zones of inhibition were not produced by sunflower honey for Trichophyton mentagrophytes, Microsporum gypseum, and Epidermophyton floccosum; by coconut honey for Microsporum gypseum, and by propolis for Epidermophyton floccosum. No zone of inhibition was exhibited by honey and propolis for Candida albicans.

Conclusion. Honey and aqueous propolis extract exhibit antifungal properties against Trichophyton rubrum, T. mentagrophytes, Microsporum gypseum, Epidermophyton floccosum and Candida albicans. Although honey and propolis have inhibitory activities against these organisms, clotrimazole is still relatively superior based on the zone of inhibition produced by the test drugs.

Key Words: honey, propolis, antifungal, dermatophyte, Candida

\section{INTRODUCTION}

Cutaneous fungal infections or dermatomycoses are among the most common communicable fungal infections affecting humans. The common etiologic agents of dermatomycoses are keratinophilic fungi called dermatophytes and Candida albicans. Dermatophytes are classified into three genera: Trichophyton, Microsporum, and Epidermophyton. Dermatomycoses caused by dermatophytes are called dermatophytoses. These may spread from person to person (anthropophilic), animal to person (zoophilic), or soil to person (geophilic). Clinical infections are commonly referred to as tinea followed by the Latin name for the involved body site, e.g. tinea capitis (scalp), tinea faciei

Corresponding author: Maria Christina R. Batac, MD, MSc Section of Dermatology Department of Medicine Philippine General Hospital University of the Philippines Manila Taft Avenue, Manila 1000, Philippines Email:mrbatac@up.edu.ph (face), tinea barbae (bearded areas), tinea corporis (trunk and extremities), tinea manuum (hand), tinea cruris (inguinal region), tinea pedis (feet), and tinea unguium (nails).

A few studies have been published regarding the incidence of dermatomycoses in the Philippines, and most 
of these are hospital-based. Tinea corporis was the most common dermatophytosis observed, while Trichophyton rubrum and Trichophyton mentagrophytes were the most frequently isolated fungi. ${ }^{1,2}$ In the out-patient clinic of the Section of Dermatology, Philippine General Hospital, dermatomycoses had figured in the top ten consults for the past 10 years. In 2018, dermatophytoses were the second most frequent reason for consult among new patients.

Dermatomycoses are frequently treated with topical antifungal agents, usually allylamines like terbinafine for dermatophytoses, and azoles like clotrimazole, miconazole, and ketoconazole for cutaneous candidiasis. Since dermatomycoses are widely prevalent, there is a need to develop cheaper and more accessible, alternative treatment regimen. There has been a growing demand for "natural remedies" which are often perceived as safe and effective, even if there are no robust studies to support their use. Honey and propolis are among the natural remedies believed to be effective against various skin lesions.

Honey, a thick, sweet liquid made by bees from the in vivo enzymatic processing of nectar, has been recognized for its medicinal properties since ancient times. It is used as an anti-infective agent to complement management of wounds, burns, and pressure ulcers. Its known antimicrobial property is attributed to its $\mathrm{pH}$, hydrogen peroxide content, osmotic effect, and as yet unidentified compounds called inhibines. ${ }^{3}$ A systematic review showed that honey is an effective wound dressing, providing reduced healing time for burns and infected postoperative wounds. ${ }^{4}$ It is also known to have antimicrobial property. Several in vitro and in vivo studies have been conducted to support this claim. A study conducted in United Arab Emirates showed that growths of Staphylococcus aureus, Streptococcus pyogenes, Escherichia coli, and Candida albicans were inhibited upon adding honey in 2-24 hour old cultures. ${ }^{5}$ The antibacterial activity of honey was attributed to its hydrogen peroxide content, nitric oxide production in various animals and humans' biological fluids, decreased prostaglandin concentration, and enhanced antibody production. ${ }^{5}$ Al-Waili (2004) investigated whether hyperosmolarity, acidity, and hydrogen peroxide content are the reasons behind the antimicrobial property of honey. ${ }^{6}$ Being a saturated solution of sugar, honey may dehydrate organisms exposed to it. In the study, whereas honey exhibited potent antimicrobial activity, glucose solution yielded very minimal antibacterial activity. In addition, growth of microorganisms in acidic medium similar to honey was not inhibited. Honey contains glucose oxidase, the enzyme responsible for hydrogen peroxide production. It becomes active when honey is diluted. However, in the same study, honey exhibited antimicrobial property even at $100 \%$ concentration. This study showed that osmolarity, acidity, and hydrogen peroxide content cannot explain comprehensively the antimicrobial property of honey. Nonperoxide factors which may influence the antimicrobial property of honey include lysozyme, phenolic acids, and flavonoids. ${ }^{7}$ The antibacterial property of honey was found to be dependent on the type of floral source, concentration of honey, and test pathogen. ${ }^{7}$

In vivo studies showed that honey promotes wound granulation, epithelialization, as well as clearance of documented bacterial infection. ${ }^{6,8}$ Its ability to promote wound healing may be due to the natural moisture it imparts on the wound as well as its vitamin $\mathrm{C}$ content, an important factor in collagen synthesis. ${ }^{6}$

In 2004, a pilot study which studied the efficacy of 4-week application of honey-olive oil-beeswax in treating pityriasis versicolor and dermatophytoses showed that 11 of 14 patients with pityriasis versicolor, 10 of 14 patients with tinea cruris and 5 of 8 patients with tinea corporis obtained clinical improvement and mycological cure. The antifungal activity of the honey mixture was attributed to the reduction of prostaglandin synthesis at the site of application, increase in nitric oxide on the affected sites, inhibition of concomitant bacterial growth, inhibition of leukotriene B4, and also to the mixture's antioxidant and anti-inflammatory properties. ${ }^{9}$ The mixture inhibited the growth of Staphylococcus aureus and Candida albicans in vitro at $66-100 \%$ concentration. ${ }^{10}$ Although there are several published studies which investigated the antibacterial property of honey, there have only been a few which studied its in vitro antifungal property, specifically its anticandidal property.

Propolis or bee glue is the brownish resinous substance collected by worker bees from various plant materials to coat hive walls, seal cracks or gaps, and embalm dead invader insects. ${ }^{11}$ Like honey, it is a natural remedy used since ancient times. It is known for its anti-putrefactive, antiseptic, cicatrizant, disinfectant, and anti-pyretic properties. Among the major components of propolis believed to be responsible for its biological activities are polyphenols such as flavonoids, accompanied by phenolic acids, esters, phenolic aldehydes, and ketones. It also contains volatile oils, aromatic acids, waxes, resins, balms, and pollen grains. Its antimicrobial property is mainly attributed to flavonoids. They are potent antioxidants, free radical scavengers, metal chelators, and inhibitors of lipid peroxidation. ${ }^{12}$

Propolis exhibited antibacterial property against Staphylococcus aureus, superior to honey. ${ }^{13}$ Propolis produced by various bees and honey gathered from different floral sources differ in their chemical composition as well as their antibacterial property. Ethanolic extract of propolis was found to completely inhibit Staphylococcus aureus, Staphylococcus epidermidis, Enterococcus sp, Corynebacterium spp, Branhamella catarrbalis, and Bacillus cereus, and partially inhibit Pseudomonas aeruginosa and Escherichia coli. ${ }^{14}$ Propolis alcoholic extracts from various geographic origin exhibited antifungal activity against Candida albicans. ${ }^{12,15,16} \mathrm{~A}$ study in Serbia showed widening of inhibition zones around discs of antibiotics on agar enriched with ethanolic extracts of propolis. This points to a possible synergistic antimicrobial 
activity between propolis and antimicrobial drugs. ${ }^{17}$ Several studies investigated the in vitro antifungal property of propolis, but this is the first time the antifungal property of Philippine propolis from stingless bees (Trigona biroi) was determined.

The aim of this study was to determine the in vitro antifungal property of honey from two different floral sources and Philippine propolis against Trichophyton rubrum, Trichophyton mentagrophytes, Microsporum gypseum, Epidermophyton floccosum, and Candida albicans.

\section{MATERIALS AND METHODS}

The antifungal property of honey from two different floral origins (sunflower [Helianthus annuus L. Family Asteraceae] and coconut [Cocos nucifera L. Family Arecacae]) and propolis for four selected species of common dermatophytes and Candida albicans was obtained by the broth macrodilution method (minimum inhibitory concentration, MIC) and the disk diffusion method (zone of inhibition). These are well-established in vitro methods that help predict clinical outcome when these test agents are administered to patients. ${ }^{18}$

\section{Operational definition of variables}

\section{Minimum Inhibitory Concentration}

In a sequence of decreasing concentrations (serial dilution) of honey, this is the lowest concentration being tested at which there is no visually observable growth in the broth after 7 days of incubation at room temperature.

\section{Zone of Inhibition}

This is the diameter in $\mathrm{mm}$ of no growth (100\% inhibition) around the treatment-impregnated disk on the inoculated Sabouraud's agar medium.

\section{Test organisms}

A total of five (5) well-characterized isolates from the Department of Medical Microbiology of the College of Public Health, University of the Philippines Manila were tested, including clinical isolates of the following species: Trichophyton rubrum, Trichophyton mentagrophytes, Microsporum gypseum, Epidermophyton floccosum, and a reference isolate of Candida albicans.

\section{Preparation of inocula}

Preparation of inoculum suspensions was based mainly on the NCCLS proposed standard (M38-P) for broth dilution antifungal susceptibility testing of conidium-forming filamentous fungi. The isolates were subcultured on Potato Dextrose Agar plates for 7-14 days at room temperature. Stock inoculum suspensions of each isolate were prepared from 7 to 14-day-old cultures. The fungal colonies were covered with $10 \mathrm{~mL}$ of distilled water, and suspensions were made by gently probing and scraping the surface with the tip of a Pasteur pipette. The resulting mixture of conidia and hyphal fragments was withdrawn and transferred to a sterile tube. Heavy particles were allowed to settle for 15 minutes and the upper homogenous suspensions were collected and mixed using a vortex mixer. The densities of $0.5 \mathrm{~mL}$ of the suspensions were read at $530 \mathrm{~nm}$ using a spectrophotometer and adjusted to $65-70 \%$ transmittance to obtain standardized inocula approximately $10^{4} \mathrm{CFU} / \mathrm{mL} .{ }^{19}$ Inoculum of $10^{4}$ $\mathrm{CFU} / \mathrm{mL}$ was also used for the disk diffusion method.

\section{Replicates}

Three replicates were done for each organism per treatment per method.

\section{Test agents}

Coconut and sunflower honey were provided by the Bee Program of the University of the Philippines at Los Baños(UPLB). The classification was based on the dominant pollen grains that were present in the honey samples. The coconut honey was produced in an apiary in Bukidnon while the sunflower honey was produced in Baguio City. The honey samples were analyzed for their physicochemical properties to ensure their authenticity. The propolis samples were obtained from stingless bee (Tetragonula biroi) colonies at the UPLB apiary. After collection, the samples were air dried to remove the excess moisture content.

Propolis water extract was prepared by mixing 3 parts propolis and 7 parts water by weight in a flask. The mixture was then shaken for 15 minutes daily for 7 days.

\section{Macrodilution method}

Ten test tubes were arranged in a rack labeled from 1 to 10 with $0.5 \mathrm{~mL}$ of decreasing concentration of honey and propolis, namely $100 \%, 90 \%, 80 \%, 70 \%, 60 \%, 50 \%$, $40 \%, 30 \%, 20 \%$, and $10 \%$. The test agents were diluted with Sabouraud's broth.

Test tubes 1 to 10 were then inoculated with $0.5 \mathrm{~mL}$ of the inoculum. A growth control, containing $0.5 \mathrm{~mL}$ of the inoculum suspension and $0.5 \mathrm{~mL}$ of the treatmentfree medium (Sabouraud's broth) was prepared for each organism and treatment tested. Sterility control was prepared by mixing $0.5 \mathrm{~mL}$ of the treatment and $0.5 \mathrm{~mL}$ of the Sabouraud's broth. With the inoculum, the final concentration $(\mathrm{v} / \mathrm{v} \%)$ of honey and propolis in tubes 1 to 10 were $67 \%, 60 \%, 53 \%, 47 \%, 40 \%, 33 \%, 27 \%, 20 \%, 13 \%$, and $7 \%$. The density of sunflower honey at $1.25 \mathrm{~g} / \mathrm{mL}$ is lower than coconut honey at $1.58 \mathrm{~g} / \mathrm{mL}$. Table 1 shows the calculated final concentration in $\mathrm{g} / \mathrm{mL}$ of the test agents for each $\mathrm{v} / \mathrm{v} \%$ dilution.

Honey/propolis-inoculum mixture and control tubes were incubated for seven days at room temperature. The minimum inhibitory concentration was determined by visual inspection. Growth inhibition in each test tube was compared to the growth control (treatment-free test tube). 
Table 1. Equivalent Concentration of Sunflower Honey, Coconut Honey, and Propolis for each Dilution

\begin{tabular}{rcccc}
$\begin{array}{c}\text { Tube } \\
\text { No. }\end{array}$ & $\mathbf{v} / \mathrm{v} \%$ & $\begin{array}{c}\text { Sunflower honey } \\
(\mathrm{g} / \mathrm{mL})\end{array}$ & $\begin{array}{c}\text { Coconut honey } \\
(\mathrm{g} / \mathrm{mL})\end{array}$ & $\begin{array}{c}\text { Propolis } \\
(\mathrm{g} / \mathrm{mL})\end{array}$ \\
\hline 1 & 67 & 0.83 & 1.05 & 0.28 \\
2 & 60 & 0.75 & 0.95 & 0.26 \\
3 & 53 & 0.67 & 0.84 & 0.23 \\
4 & 47 & 0.58 & 0.74 & 0.20 \\
5 & 40 & 0.50 & 0.63 & 0.17 \\
6 & 33 & 0.42 & 0.53 & 0.14 \\
7 & 27 & 0.33 & 0.42 & 0.11 \\
8 & 20 & 0.25 & 0.32 & 0.08 \\
9 & 13 & 0.17 & 0.21 & 0.06 \\
10 & 7 & 0.08 & 0.10 & 0.03 \\
\hline
\end{tabular}

\section{Disk Diffusion Method}

Petri dishes, $100 \mathrm{~mm}$ in diameter were filled with 15 $\mathrm{mL}$ of solid Sabouraud's medium. ${ }^{20}$ The solidified medium was inoculated by dipping a sterile swab in the prepared $10^{4}$ spore suspension and streaking it across the surface of the agar. After drying the plates at room temperature for 15 minutes, the treatment-impregnated $6 \mathrm{~mm}$ disks (100\% honey, propolis extract and 1\% clotrimazole solution (Canesten)) were applied on the agar. The agar plates were incubated at $28^{\circ} \mathrm{C}$ for 7 days. The zone of inhibition diameter was measured in $\mathrm{mm} .{ }^{21}$

\section{Data Analysis}

The MIC and zone of inhibition mode and range values for each treatment and for each organism were determined.

\section{RESULTS}

\section{Minimum inhibitory concentration}

Sunflower honey had antifungal effects against all the tested organisms. It was found to best inhibit Trichophyton mentagrophytes (MIC=0.25 g/mL), Microsporum gypseum (MIC $=0.25 \mathrm{~g} / \mathrm{mL}$ ), and Candida albicans (MIC= $=0.25 \mathrm{~g} /$ $\mathrm{mL}$ ), and least inhibit Epidermophyton floccosum (MIC=0.58 $\mathrm{g} / \mathrm{mL}$ ). Coconut honey exhibited antifungal effect against most of the dermatophytes but it was not observed to inhibit Microsporum gypseum. It was also found to best inhibit Trichophyton mentagrophytes $(\mathrm{MIC}=0.10 \mathrm{~g} / \mathrm{mL}$ ) among all the organisms tested.

Although sunflower honey had antifungal effect against all the tested fungi, coconut honey showed lower MICs compared to sunflower honey.

Propolis had lower MICs compared to both honey preparations except against Microsporum gypseum. It best inhibited Trichophyton mentagrophytes (MIC $=0.08 \mathrm{~g} / \mathrm{mL})$ and least inhibited Microsporum gypseum (MIC $=0.28 \mathrm{~g} / \mathrm{mL}$ ).

\section{Zone of inhibition}

Sunflower honey did not produce any zone of inhibition for Trichophyton mentagrophytes, Microsporum gypseum, and
Epidermophyton floccosum. Coconut honey did not produce any zone of inhibition for Microsporum gypseum. Zone of inhibition was not produced by propolis for Epidermophyton floccosum. The size of the zone of inhibition produced by the highest concentration of the test agent was noted to increase as the MIC decreased (Table 2). No zone of inhibition was exhibited by honey and propolis for Candida albicans. Clotrimazole produced significantly wider zones of inhibition against all the microorganisms tested compared to honey and propolis.

Table 2. Minimum Inhibitory Concentration of Sunflower Honey, Coconut Honey, Propolis, and Clotrimazole against 4 Different Dermatophytes and Candida albicans

\begin{tabular}{|c|c|c|c|c|}
\hline Fungus & Treatment & $\begin{array}{l}\text { MIC } \\
\text { mode } \\
(\mathrm{g} / \mathrm{mL})\end{array}$ & $\begin{array}{l}\text { MIC } \\
\text { range } \\
\text { (g/mL) }\end{array}$ & $\begin{array}{c}\text { Zone of } \\
\text { inhibition } \\
(\mathrm{mm})^{*}\end{array}$ \\
\hline \multirow{4}{*}{$\begin{array}{l}\text { Trichophyton } \\
\text { rubrum }\end{array}$} & Sunflower honey & 0.42 & $0.33-0.42$ & 12 \\
\hline & Coconut honey & 0.32 & $0.21-0.32$ & 12 \\
\hline & Propolis & 0.11 & 0.11 & 22 \\
\hline & Clotrimazole & & & 51 \\
\hline \multirow{4}{*}{$\begin{array}{l}\text { Trichophyton } \\
\text { mentagrophytes }\end{array}$} & Sunflower honey & 0.25 & 0.25 & 6 \\
\hline & Coconut honey & 0.10 & 0.10 & 21 \\
\hline & Propolis & 0.08 & $0.08-0.11$ & 26 \\
\hline & Clotrimazole & & & 58 \\
\hline \multirow{4}{*}{$\begin{array}{l}\text { Microsporum } \\
\text { gypseum }\end{array}$} & Sunflower honey & 0.25 & 0.25 & 6 \\
\hline & Coconut honey & $>1.05$ & $>1.05$ & 6 \\
\hline & Propolis & 0.28 & 0.28 & 16 \\
\hline & Clotrimazole & & & 44 \\
\hline \multirow{4}{*}{$\begin{array}{l}\text { Epidermophyton } \\
\text { floccosum }\end{array}$} & Sunflower honey & 0.58 & $0.50-0.58$ & 6 \\
\hline & Coconut honey & 0.21 & 0.21 & 11 \\
\hline & Propolis & 0.11 & $0.11-0.14$ & 6 \\
\hline & Clotrimazole & & & 39 \\
\hline \multirow{4}{*}{ Candida albicans } & Sunflower honey & 0.25 & 0.25 & 6 \\
\hline & Coconut honey & 0.32 & $0.21-0.42$ & 6 \\
\hline & Propolis & 0.14 & $0.06-0.14$ & 6 \\
\hline & Clotrimazole & & & 34 \\
\hline
\end{tabular}

${ }^{*}$ Size of disk $=6 \mathrm{~mm}$

\section{DISCUSSION}

Studies on the antifungal property of honey and propolis are few, and most of those published focus on anticandidal activity, rather than antidermatophytic property. This study showed that honey obtained from two different floral sources (sunflower and coconut) and propolis exhibit antifungal property which differed according to floral source and test microorganism. The difference in floral sources may lead to differences in honey components and characteristics, including antimicrobial property. This may explain the difference observed in the antifungal property between sunflower honey and coconut honey.

A study done in Turkey investigated the antifungal property of ethanolic extract of propolis against Trichophyton 
rubrum and T. mentagrophytes. Propolis had an MIC of 0.025$0.4 \mathrm{ug} / \mathrm{mL}$ against T. rubrum and $0.1-0.8 \mathrm{ug} / \mathrm{mL}$ against $T$. mentagrophytes. ${ }^{22}$ These values are much lower than the one obtained in this study. The difference may be attributed to the fact that aqueous extract of propolis was utilized in this study instead of ethanolic extract. In addition, variation in results may also be due to the difference in the method of determining the MIC. Various studies identify flavonoids as the components mainly responsible for the antimicrobial property of honey and propolis. They are known potent antioxidants, free radical scavengers, metal chelators, and inhibitors of lipid peroxidation. ${ }^{12}$ Future studies can embark on isolating substances from honey and propolis and testing these extracts for antifungal property.

Since honey is a natural product, it is important to determine the effect of bee species, geographical and botanical origin, processing, and storage on its antifungal property. The composition of propolis likewise varies according to the plants available in the region leading to possible differences in the antimicrobial property of the substance. ${ }^{23}$ It is therefore useful to determine which plant source and which bee can produce the propolis in the country with the best antimicrobial activity. Although this study showed that honey and propolis exhibit antifungal property, they do so at high concentrations, making it difficult to incorporate them in medical formulations as active components. However, their synergistic activity with antimicrobial drugs may be further investigated and maximized.

\section{CONCLUSION}

Honey and aqueous propolis extract exhibit antifungal property against Trichophyton rubrum, T. mentagrophytes, Microsporum sypseum, Epidermophyton floccosum, and Candida albicans. Although honey and propolis have inhibitory activity against these organisms, clotrimazole is still relatively superior based on the zone of inhibition produced by the test drugs.

\section{Acknowledgment}

The researchers wish to acknowledge the assistance of Mr. Alex Fajardo of the University of the Philippines at Los Baños Bee Program.

\section{Statement of Authorship}

Batac: protocol development, procurement of materials, conduct of laboratory procedures, data collection, analysis and writing of paper. Sison: conduct of laboratory procedures, data collection. Cervancia: consulted during protocol development, procurement of materials, gave valuable inputs in the final version of paper. Nicolas: protocol development, project supervision. All authors have approved the final version submitted.

\section{Author Disclosure}

All authors declared no conflict of interest.

\section{Funding Source}

This paper was funded by the authors.

\section{REFERENCES}

1. Reyes AC, Jacalne A V. The etiology of superficial mycoses in the Philippines. J Philipp Med Assoc. 1962; 38:393-400.

2. Gutierrez GT, Lazaro-Medina A, Punzalan A. Dermatomycoses at the Philippine General Hospital. Acta Med Philipp. 1982; 18(1):10-16.

3. Namias N. Honey in the management of infections. Surg Infect (Larchmt). 2003; 4(2):219-26. doi:10.1089/109629603766957022.

4. Moore OA, Smith LA, Campbell F, Seers K, McQuay HJ, Moore RA. Systematic review of the use of honey as a wound dressing. BMC Complement Altern Med. 2001;1:2. doi:10.1186/1472-6882-1-2.

5. Al-Waili NS, Akmal M, Al-Waili FS, Saloom KY, Ali A. The antimicrobial potential of honey from United Arab Emirates on some microbial isolates. Med Sci Monit. 2005;11(12):BR433-8.

6. A1-Waili NS. Investigating the antimicrobial activity of natural honey and its effects on the pathogenic bacterial infections of surgical wounds and conjunctiva. J Med Food. 2004;7(2):210-22.

7. Taormina PJ, Niemira BA, Beuchat LR. Inhibitory activity of honey against foodborne pathogens as influenced by the presence of hydrogen peroxide and level of antioxidant power. Int J Food Microbiol. 2001; 69(3):217-25. doi:10.1016/S0168-1605(01)00505-0.

8. Al-Waili NS, Saloom KY. Effects of topical honey on post-operative wound infections due to gram positive and gram negative bacteria following caesarean sections and hysterectomies. Eur J Med Res. 1999; 4(3):126-30.

9. Al-Waili NS. An alternative treatment for pityriasis versicolor, tinea cruris, tinea corporis and tinea faciei with topical application of honey, olive oil and beeswax mixture: an open pilot study. Complement Ther Med. 2004; 12(1):45-7.

10. Al-Waili NS. Mixture of honey, beeswax and olive oil inhibits growth of Staphylococcus aureus and Candida albicans. Arch Med Res. 2005; 36(1):10-3.

11. Castaldo S, Capasso F. Propolis, an old remedy used in modern medicine. Fitoterapia. 2002; 73 Suppl 1:S1-6. doi:10.1016/S0367326X(02)00185-5.

12. Prytzyk E, Dantas AP, Salomão K, Pereira AS, Bankova VS, De Castro $\mathrm{SL}$, et al. Flavonoids and trypanocidal activity of Bulgarian propolis. J Ethnopharmacol. 2003; 88(2-3):189-93. doi:10.1016/S0378-8741 (03)00210-1.

13. Miorin PL, Levy Junior NC, Custodio AR, Bretz WA, Marcucci MC. Antibacterial activity of honey and propolis from Apis mellifera and Tetragonisca angustula against Staphylococcus aureus. J Appl Microbiol. 2003; 95(5):913-20. doi:10.1046/j.13652672.2003.02050.x.

14. Grange JM, Davey RW. Antibacterial properties of propolis (bee glue). J R Soc Med. 1990; 83(3):159-60.

15. Kujumgiev A, Tsvetkova I, Serkedjieva Y, Bankova V, Christov R, Popov S. Antibacterial, antifungal and antiviral activity of propolis of different geographic origin. J Ethnopharmacol. 1999;64(3):235-40.

16. Silici S, Koç N a, Ayangil D, Cankaya S. Antifungal activities of propolis collected by different races of honeybees against yeasts isolated from patients with superficial mycoses. J Pharmacol Sci. 2005;99(1):39-44. doi:10.1254/jphs.FPE05002X.

17. Stepanović S, Antić N, Dakić I, Svabić-Vlahović M. In vitro antimicrobial activity of propolis and synergism between propolis and antimicrobial drugs. Microbiol Res. 2003;158(4):353-7. doi:10.1078/0944-5013-00215.

18. Espinel-Ingroff A, Warnock DW, Vazquez JA, Arthington-Skaggs BA. In vitro antifungal susceptibility methods and clinical implications of antifungal resistance. Med Mycol. 2000; 38(Suppl 1):293-304.

19. Fernández-Torres B, Cabañes FJ, Carillo-Muñoz AJ, Esteban A, Inza I, Abarca L, et al. Collaborative evaluation of optimal antifungal susceptibility testing conditions for dermatophytes. J Clin Microbiol. 2002; 40(11):3999-4003. doi:10.1128/JCM.40.11.3999-4003.2002. 
20. Macura $A B$. In vitro susceptibility of dermatophytes to antifungal drugs: a comparison of two methods. Int J Dermatol.1993; 32(7):533-6.

21. Karaca N, Koc AN. In vitro susceptibility testing of dermatophytes: comparison of disk diffusion and reference broth dilution methods. Diagn Microbiol Infect Dis. 2004; 48(4):259-64.

22. Koc AN, Silici S, Ayangil D, Ferahbas A, Cankaya S. Comparison of in vitro activities of antifungal drugs and ethanolic extract of propolis against Trichophyton rubrum and T-mentagrophytes by using a microdilution assay. Mycoses. 2005; 48(3):205-10.

23. Silici S, Kutluca S. Chemical composition and antibacterial activity of propolis collected by three different races of honeybees in the same region. J Ethnopharmacol. 2005; 99(1):69-73. doi:10.1016/j. jep.2005.01.046.

The Acta Medica Philippina is now accepting original scientific papers, review articles and case reports for its upcoming issues. Please follow the format for submission as indicated in the "Instructions to Authors" elsewhere in the journal. All papers received shall be properly acknowledged. For inquiries and submission of proposals, please email us at actamedicaphilippina.upm@up.edu.ph 